Research Article

\title{
The Determinants of the Nondefaultable Spreads of Corporate Bonds: Evidence from China
}

\author{
Baochen Yang, Zijian $W u(D$, and Yunpeng Su \\ College of Management and Economics, Tianjin University, Tianjin 300072, China \\ Correspondence should be addressed to Zijian Wu; zjwu@tju.edu.cn and Yunpeng Su; ypsu@tju.edu.cn
}

Received 5 February 2021; Accepted 19 June 2021; Published 1 July 2021

Academic Editor: Xiao Li

Copyright (c) 2021 Baochen Yang et al. This is an open access article distributed under the Creative Commons Attribution License, which permits unrestricted use, distribution, and reproduction in any medium, provided the original work is properly cited.

\begin{abstract}
This study investigates the factors impacting the price difference between the interbank market and the exchange market for the same bond using a large transaction dataset from July 2006 to June 2016 in China. We find that market liquidity and macrofactors mainly affect the price difference between the two markets for the same bond. And individual bond liquidity explains only a small part of the price difference. We also find that the interaction between liquidity and credit risk is an important factor affecting the price difference, and the effect is greater during financial crisis.
\end{abstract}

\section{Introduction}

The value of China's bond market exceeded 91 trillion yuan in issues by the end of May 2019, making it the world's second-largest bond market after that of the US. China's corporate bond market is divided into an interbank market and an exchange market. In the interbank bond market, commercial banks, insurance companies, security companies, and other financial institutions buy, sell, and repurchase bonds. Participants in this bond market make inquiries to close deals with selected counterparties. On the contrary, the exchange bond market is dominated by nonbank financial institutions and individuals. Bond trading in the exchange market, such as stock trading, is conducted by many investors bidding together and negotiated by actuarial institutions.

There are two types of corporate bonds in China. One type is issued by a department of the central government or a state-owned enterprise, while the other is issued by listed companies. The first corporate bond type is traded on both the exchange market and the interbank market, whereas the second type of corporate bond is traded only on the exchange market. The first type was issued earlier and is larger in size than the second type.

China's corporate bond market began to sprout as early as the 1980s. Since then, China has transitioned from a planned economy to a market economy. In August 1993, the "corporate bond management regulations" were promulgated by the State Council, and the first type of corporate bond began to be issued. The regulations require issuers raising funds for the construction of large- and mediumsized projects in China to declare an issue of at least 1 billion yuan. From the beginning of 2006, the first type of corporate bonds grew rapidly. By the end of 2015, the first type of corporate bond issuance had grown in value to reach 16.82 trillion yuan (Chinese monetary unit), and the volume of transactions had reached 675.13 trillion yuan. By comparison, the second type of corporate bonds started late. On August 14, 2007, "the company's bond issuance pilot approach" was promulgated by China Securities Regulatory Commission, and on September 24, 2007, the 07 Yangtze Power bond was issued for the first time. The two types of corporate bonds are fixed-income securities based on an enterprise's credit and are important channels for the enterprise to raise funds directly from the public.

Most of the first type of corporate bonds in China is each traded simultaneously in both the interbank market and the exchange market. However, there are price differences when the same bond is traded in the two markets at the same time. The price difference for the same bond equals the difference in the spread between them, because the same Treasury interest rate for the same bond in both markets is subtracted 
when calculating the spreads. Through detailed descriptive statistics about the pricing difference between the two markets, we find mean is $0.46 \%$ and standard deviation is $0.49 \%$, as is shown in Figure 1. What causes the price difference? Some scholars analyze the investor structure of the two markets and argue that the different types of participants in the two markets result in different compensation for liquidity.

We adopt a different approach. From the perspective of individual bonds, we investigate the factors impacting the liquidity on bond spreads from different dimensions, including trading activity and price shocks, using a large transaction dataset for a 10-year period in China. Moreover, we introduce stock market liquidity and macrofactors and find that both of them affect bond spreads. Our study also finds that interaction between credit risk and liquidity is an important factor influencing bond spreads, and this effect is greater during financial crisis. Specifically, we investigate a large transaction dataset from July 2006 to June 2016, including the monthly data of 3716 bonds in China's bond market. We identify 1224 individual bonds that are traded simultaneously in the exchange market and the interbank market. Our sample includes the 2007-2008 crisis period and contains more comprehensive information from China's corporate bond market. We consider structural differences between the interbank market and the exchange bond market.

This study aims to provide a deeper understanding of the influencing factors of the price difference of the two markets for the same bond in China. Our research contributes to the literature in four ways.

First, we select corporate bonds traded simultaneously in both the interbank market and the exchange market as the sample and take the difference between the prices of the two markets for the same bond to eliminate the effect of credit risk on spreads. Scholars mainly adopt two methods when studying the influencing factors of spreads. The first category is based on the principle that credit risk proxies are controlled [1-4]. The second category is based on the principle of taking price differences between bonds with similar credit characteristics so that the credit risk component is approximately separated from spreads $[5,6]$. Longstaff et al. [6] strip the credit risk and extract liquidity risk by using the residual in the credit default swap market. Helwege et al. [5] investigate the nondefault spread by using matched pairs of bonds based on Crabbe and Turner [7] and Dick-Nielsen et al. [1]. Our sample comprises the same bonds traded in both markets, and thus, each same bond has the same credit risk. Our method of eliminating the effect of credit risk on spreads is more accurate and reliable than those used in the existing literature.

Second, we decompose yield spreads into three parts: a liquidity component, a credit risk component, and the interaction between liquidity and credit risk, and our finding that the interaction between liquidity and credit risk significantly affects spreads is in line with that of Rossi [8]. Moreover, we study temporal effect of the interaction between liquidity and credit risk on bond spreads, especially during the global financial crisis of 2008/2009.

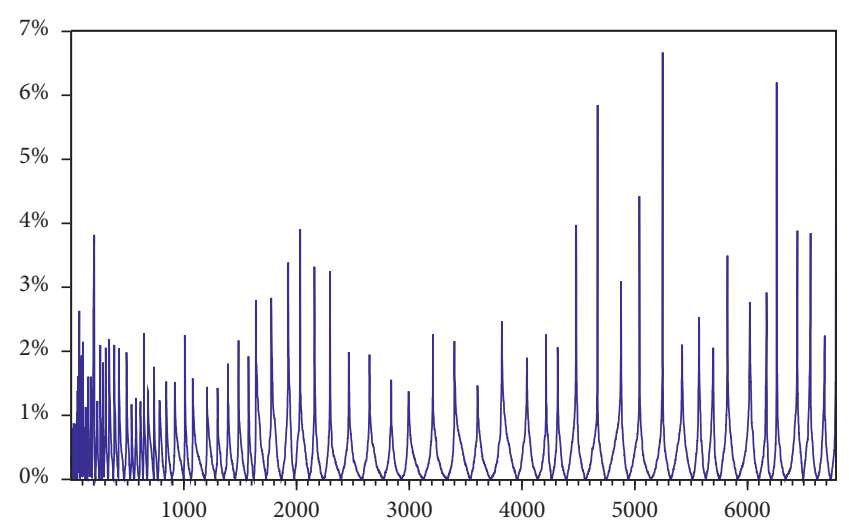

FIGURE 1: The price differences between the interbank market and the exchange market in China.

Third, we study the influence of bond market liquidity and stock market liquidity on spreads from the two dimensions of trading activity and price shocks. The effects of individual bond liquidity and market-level liquidity on bond spreads are compared.

Finally, we study the influence of macrofactors on the price difference of the two markets for the same bond. We use several macrovariables to explain the price differences, including inflation; GDP; monetary policy; the difference between the 10-year treasury rate, the 2-year treasury rate, and the 3-month treasury rate; and the spread between the bond market index yield and the 10-year Treasury rate.

Our main findings are as follows: market liquidity and macrofactors mainly affect the price difference between the two markets for the same bond. Stock market information can significantly explain the price difference, and the stock market has liquidity spillover effects on the bond market. Similar results are obtained by Chordia et al. [9] and Goyenko and Ukhov [10]. And individual bond liquidity explains only a small part of the price difference. The interaction between liquidity and credit risk is an important factor affecting the price difference, and the effect is greater during financial crisis.

Overall, our research provides new channels to explain the price difference of the two markets for the same bond at the same time, which is of great significance to bond pricing and risk hedging.

The rest of this paper is organized as follows. Section 2 presents a literature review. Section 3 provides the empirical model. Section 4 describes the variables, data, and sample. Section 5 elaborates on the empirical results. Section 6 outlines the results of the robustness tests. Section 7 analyzes the timing characteristics of the interaction between liquidity and credit risk. Finally, Section 8 concludes.

\section{Literature Review}

Many scholars have studied the impact of corporate bond spreads on different aspects, including individual liquidity, market-level liquidity, and macrofactors [11-15]. It is well documented that corporate bond spreads are explained by individual liquidity [16-24]. Roll [23] shows that under 
certain assumptions, the percentage bid-ask spread of corporate bonds is double the square root of the minus covariance between consecutive returns. Amihud [16] constructs a proxy of illiquidity measure based on the theoretical model of Kyle [25], while Downing et al. [21] construct range of bond prices as a liquidity measure. Ren and $\mathrm{Li}$ [26] construct the pricing model of defaultable bonds under the influence of liquidity risk and find that the term structure of bond spreads is very sensitive to liquidity risk. Chen et al. [18] use zero trading days to measure liquidity. Helwege et al. [5] use many liquidity proxies to explain corporate bond spreads, including efficient individual liquidity measures.

With regard to the impact of market-level liquidity on corporate bond spreads, Brockman and Chung [27] show that commonality in liquidity includes both market and industry components. Comerton-Forde et al. [28] find that aggregate market-level and specialist firm-level spreads widen when specialists have large positions or lose money. Helwege et al. [5] use a regression model to test whether market-level liquidity measures help to explain the differences in bond spreads and find that they significantly improve explanatory power. Ji and Cao [29] find that spreads more reflect market liquidity premium rather than credit risk premium. Bongaerts et al. [30] find that the liquidity level and exposure to equity market liquidity risk affect expected bond returns, while exposure to corporate bond liquidity shocks carries an economically negligible risk premium. These studies provide evidence supporting the impact of market liquidity on corporate bond spreads. This impact cannot be ignored, because there is a systematic liquidity factor that affects corporate bond spreads by affecting market liquidity. Many scholars have found evidence of systematic liquidity factors [9, 31-36]. Chordia et al. [9] provide evidence of a systematic liquidity factor in the bond market and find that this is related to a contemporaneous systematic liquidity factor of the stock market. Brockman et al. [31] find that a systematic liquidity factor exists in the stock market. Mancini et al. [36] conclude that there is a systematic liquidity factor in the foreign exchange market, which is linked to equity market liquidity. In addition, several works in the literature provide evidence on whether the systematic liquidity risk is priced [33,37-40]. Pástor and Stambaugh [39]; Acharya and Pedersen [37]; and Sadka [40] demonstrate that a premium of systematic liquidity risk exists. Sadka [40] provides evidence that the shocks of systematic liquidity are persistent.

The third category focuses on the causal relationship between macrofactors and corporate bond spreads. Küçük [41] studies the effects of macroeconomic variables on the nondefault component of emerging market yield spreads. Han and Zhou [42] focus on the linkage between the nondefaulting component and the macroeconomic conditions. Guo et al. [43] find that monetary policy have a more significant effect on spreads for medium-to-long-term corporate bond but have little impact on the short term. Ludvigson and $\mathrm{Ng}$ [44] investigate the linkages between macrofactors and bond risk premia. Vodova [45] find that monetary policy negatively impacts market liquidity. Valla et al. [46]; Dinger [47]; and Vodova [45] find a negative impact of GDP on market liquidity. In addition, Moussa [48] finds that inflation and market liquidity are closely correlated. See also Singh and Sharma [49], who propose that macrofactors affect corporate bond spreads by affecting market liquidity.

Some scholars eliminate the credit risk component in order to further study the influence of the nondefault component on spreads. In this regard, two major approaches are adopted. The first is based on the principle of controlling the credit risk component [1-4]. Longstaff [2] investigates the impact of liquidity on the spreads between Treasury and Refcorp bonds by controlling credit risk. Dick-Nielsen et al. [1] investigate the contribution of illiquidity to corporate bond spreads by controlling credit risk and bond characteristics. Shin and Kim [3] use a similar approach to study the impact of liquidity on yield spreads. These works reflect the principle of controlling credit risk. The second approach is based on the principle of approximately separating out the credit risk component from the bond spreads $[5,11]$. Instead of credit controls, Dick-Nielsen et al. [1] run regressions on a matched sample of corporate bonds using pairs of bonds issued by the same firm with maturity close to each other. Helwege et al. [5] separate out the credit risk component by examining bonds that are issued by the same firm and examine the effects of liquidity in a sample of bond pairs. Ejsing et al. [11] extract liquidity premia and estimate liquidity and credit premia as latent factors in a state-space framework.

Several studies discuss the effect of liquidity and credit risk on bond spreads [50-52]. In fact, the previous literature regarding the above tends to focus on how liquidity or the credit component contributes to yield spreads independently. Thus, these works tend to overlook whether an interaction between liquidity and credit risk exists. Duffie and Singleton [51] allow for liquidity effects by introducing a stochastic process as the fractional carrying cost of the defaultable instrument. Ericsson and Renault [52] investigate the interaction between liquidity and credit risk in theory and establish the existence of a credit component, a liquidity component, and an interaction term. He and Xiong [53] develop a theoretical model to analyze the interaction between debt market liquidity and credit risk through socalled rollover risk. He and Milbradt [54] show that corporate default decisions interact with endogenous secondary market liquidity via the rollover channel. Wang and $\mathrm{Wu}$ [55] study the relation between trading variables and price volatility and find strong evidence of a significant interactive effect of liquidity and credit risk, magnifying during the financial crisis period. Sperna Weiland et al. [56] propose a novel way of modeling credit-liquidity interactions through mutually exciting processes and find that, on average, the credit-induced liquidity component accounts for $8 \%$ to $17 \%$ of total yield spreads, but in the most distressed periods, it can account for more than $40 \%$. Chen et al. [50] develop a structural credit risk model to examine how the interactions of liquidity and default risk affect corporate bond pricing.

Most of these studies discuss the impact of the interaction term on corporate bond spreads by focusing on a 
theoretical model, whereas this study investigates the impact of the interaction term on the nondefault spread by separating out the credit risk component from the bond spreads through different empirical methods. Our empirical analysis reveals the impact of the interaction term on the nondefault spread in China's corporate bond market. We provide evidence of the impact of the interaction between liquidity and credit risk on the nondefault spread from the cross-market perspective. Several studies show that the bond market and stock market have liquidity spillover effects [9, 57, 58]. Chordia et al. [9] investigate liquidity movements in Treasury bond and stock markets over a period of more than 1800 trading days and find that bond and stock market liquidity are significantly correlated. Goyenko and Ukhov [10] provide evidence of liquidity linkage between bond and stock markets. They propose that stock market liquidity affects the bond market. Dimic et al. [57] find that timevarying stock-bond correlation patterns vary significantly between the time horizons. However, Chordia et al. [9]; Goyenko and Ukhov [10]; and Dimic et al. [57] do not consider the interaction between liquidity and credit risk. We investigate the impact of the interaction between liquidity and credit risk on the nondefault spread from different liquidity dimensions of bond market liquidity and stock market liquidity. Our results show that the nondefault spread can be significantly explained by the interaction between liquidity and credit risk considering stock market liquidity bond market liquidity.

In summary, the previous literature provides an important foundation for this study. Few of above research study price difference between the interbank market and the exchange market, which will be studied in this paper.

\section{Model}

Referring to Helwege et al. [5] and Dick-Nielsen et al. [1], we select corporate bonds traded simultaneously in both the interbank market and the exchange market and take the difference between the prices of the two markets for the same bond to eliminate the effect of credit risk on spreads accurately. We study the determinants of the price difference of the two markets for the same bond in China's corporate bond market. Equation (1) presents a new model, which eliminates the credit risk:

$$
\text { Price_dif }{ }_{j t}=\alpha_{0}+\alpha_{1} \times \text { Liq_dif }_{j t}+\alpha_{4} \times \text { Inter_dif }_{j t}+\varepsilon_{j t} .
$$

In equation (1), Price_dif $f_{j t}$ is the difference between the exchange market and the interbank market in price of the individual bond, which is equal to spread difference. And Liq_dif ${ }_{j t}$ is the difference between the exchange market and the interbank market in liquidity of the individual bond. Inter_dif $j t$ is the difference between the exchange market and the interbank market in the interaction between liquidity and credit risk of the individual bond.

Equations (2)-(4) present new models that include market-level liquidity and macrofactors:

$$
\begin{aligned}
& \text { Price_dif }{ }_{j t}=\alpha_{0}+\alpha_{1} \times \text { Liq_dif }_{j t}+\alpha_{2} \times \text { Mar_liq }_{j t}+\alpha_{4} \times \text { Inter_dif } \\
& j t
\end{aligned}
$$

Mar_liq $q_{j t}$ are the market-level liquidity proxies, and $\mathrm{Mac}_{j t}$ are the macrofactor proxies.

\section{Variables, Data, and Sample}

4.1. Liquidity and Credit Proxies. Referring to Shin and Kim [3], we choose the following five liquidity measures in order to comprehensively measure the liquidity premium: Turnover, Vol, Day, Amihud, and Range. Turnover, the frequency with which market assets trade in a certain period, is one of the most important proxies to reflect trading activity of the market. Vol is obtained by dividing the total trading volume with the number of months during which the issue is traded. Day is defined as the number of trading days in the corresponding month. If the number of trading days is larger, the bond is more active. Amihud [16] constructs a proxy of illiquidity measure based on the theoretical model of Kyle
[25]. Following the Amihud measure, this study constructs Amihud, a monthly illiquidity measure to describe liquidity. It also constructs Range, one of the illiquidity measures used by Downing et al. [21]. Amihud and Range describe the liquidity measure of the price shocks' impact dimension.

In this study, two credit risk variables are considered as explanatory variables, Rating and Coupon. Rating is the credit rating assigned to each bond. Our study adopts the coding method of Covitz and Downing [19] and Shin and Kim [3] for credit ratings: $\mathrm{AAA}=1, \mathrm{AA}+=2, \ldots$, and $\mathrm{C}=14$. This study assigns the credit rating of bonds below $\mathrm{C}$ to 15 . In this way, we can quantify the credit level of the bond. Coupon refers to the coupon rate of the individual bond. Longstaff et al. [6] provide evidence that coupon is a proxy of the nondefaulting component of bond yield spreads and find that the coefficient of coupon is significant at least at the level of $10 \%$. Bharath and Shumway [59] provide the results of 
regressing bond spreads on coupon and find that coupon has a significantly positive correlation with bond spreads. See also Chen et al. [60] and Lin et al. [61].

4.2. Data and Sample Description. This study uses a sample of corporate bonds in the WIND database from July 2006 to June 2016. This study collects data on bond liquidity and credit risk from the WIND database, and bonds without transactions are removed. When bonds have less than 1 year's remaining trading time, they are often eliminated [5]. Thus, the corresponding observations are eliminated from the sample.

This study identifies 1224 individual bonds traded simultaneously in the exchange market and the interbank market in China as the sample. In addition, this study collects data for the trading volume, trading days, yield-tomaturity, highest price, lowest price, average price, remaining life, age, credit rating, coupon rate, and historical price, and the proxies of liquidity and credit risk are calculated based on the above data. This study calculates the differences of liquidity proxies. We calculate the price difference of the two markets for the same bond and analyze its determinants in China's corporate bond market.

4.3. Summary Statistics. The summary statistics for the variables and the bond characteristics of the sample used in this study are summarized in Table 1.

4.4. Pairwise Correlation Test. Table 2 shows the pairwise correlation coefficients between liquidity proxies and summarizes the differences in liquidity measures.

Bond trading activity can represent the level of liquidity of bonds. Turnover, Vol, and Day are the liquidity proxies of the bond transaction. Therefore, we need to investigate the degree of correlation between them. As confirmed from Panel A of Table 2, Turnover and Vol are highly positively correlated, with a correlation coefficient of 0.8724 , while Turnover and Day seem to be quite weakly correlated, as are Vol and Day. The reason is that if the trading volume of the bond is high, the number of investments involved is large, and thus, turnover is also large in China's corporate bond market. However, trading days are determined by the market structure, for example, there are fewer trading days in the interbank market, which comprises more institutional investors than the exchange market. Similar to Panel A, in Panel B, Turnover_diff and Vol_diff are highly positively correlated, with a correlation coefficient of 0.8661 . Turnover_diff and Day_diff have a very weak correlation, with a correlation coefficient of 0.2082 , while the correlation coefficient of Vol_diff and Day_diff is only slightly larger at 0.2555. Amihud and Range are often used to measure the impact of trading volume on prices and are commonly used as liquidity proxies. In Table 2 , Amihud is positively correlated with Range, with a correlation coefficient of 0.8343 , and Amihud_diff and Range_diff are also highly positively correlated, with a correlation coefficient of 0.8307 . This shows that Amihud and Range are highly correlated.
Furthermore, in Panel B, Turnover_diff and Vol_diff have the highest correlation, with a correlation coefficient of 0.8661, while the correlation of Vol_diff and Range_diff is lowest, with a correlation coefficient of -0.0862 .

\section{Empirical Results}

5.1. Summary Statistics of Liquidity Differences. This study extracts the nondefault spread, which includes the liquidity component and the interaction between liquidity and credit risk, by calculating the individual bond price difference between the exchange market and the interbank market and then analyzes its determinants. By establishing a regression model of the liquidity difference and spread difference, this study investigates the impact of liquidity on the nondefault spread. Summary statistics of liquidity differences are given in Table 3.

\subsection{Impact of the Interaction between Liquidity and Credit} Risk on Spreads. Our results show that individual liquidity proxies have a significant effect on the price difference of the two markets for the same bond. In Tables 4 and 5, the credit risk is eliminated, and the interaction between liquidity and credit risk is taken into account to study the marginal impact of liquidity proxies on spreads, respectively. To investigate the impact of liquidity, each regression is estimated using only one measure of liquidity and the interaction between liquidity and credit risk is controlled. Vol_diff, Day_diff, and Range_diff are used to represent individual liquidity difference, while the cross-terms represent the interaction between liquidity and credit risk, which cannot be removed due to their nonlinear functional relationship. Table 4 shows the estimated effects of liquidity on bond spreads and regressions using the Spread_dif as the dependent variable, including the subsamples and the full sample. We test all the error terms in the regressions in the paper and find that the error terms of the regression equations are normally distributed and stationary, in line with the basic assumptions of the regression model.

The results show that there is a significant interaction between liquidity and credit risk. In the full sample of Tables 4 and 5, the coefficients of the liquidity measures are smaller when credit risk is completely controlled. The estimated effects of liquidity in Table 5 are nearly always lower than those in Table 4 . The reason is that the liquidity proxy explains the components of credit risk, which shows that there is a significant interaction between liquidity and credit risk. Similar results can be found from Vol and Day. In Tables 4 and 5, the coefficient of Vol decreases from -0.0018 to -0.0012 , while the coefficient of Day decreases from 0.1596 to 0.0647 in the full sample. Similar results are found in the subsamples of high rating bonds and low rating bonds in Tables 4 and 5. The coefficients of the liquidity measures in Table 5 are smaller than those in Table 4 . For example, the coefficient of Vol drops from -0.0022 to -0.0010 in the high rating bonds of Tables 4 and 5 while it declines from -0.0015 to -0.0014 in the low rating bonds. The coefficient of Day drops from 0.0809 to 0.0529 in the high rating bonds of 
TABLE 1: Summary statistics of bonds in the sample.

\begin{tabular}{lcccccccc}
\hline & Mean & Median & Maximum & Minimum & Std. dev. & Jarque-Bera & Probability & Observations \\
\hline Spread & 2.7281 & 2.6652 & 35.5890 & 0.0506 & 1.1285 & 2479641.0000 & 0.01 & 13722 \\
Turnover & 0.0724 & 0.0311 & 2.1587 & 0.0001 & 0.1204 & 934967.7000 & 0.01 & 13722 \\
Vol & 79.2567 & 36.6094 & 2810.1350 & 0.0102 & 125.5374 & 1289959.0000 & 0.01 & 13722 \\
Day & 4.6155 & 2.0000 & 23.0000 & 1.0000 & 5.3099 & 11975.5100 & 0.01 & 13722 \\
Amihud & 0.0153 & 0.0004 & 3.5210 & 0.0001 & 0.1019 & 106000000.0000 & 0.01 & 13722 \\
Range & 0.0256 & 0.0006 & 5.6814 & 0.0001 & 0.1602 & 108000000.0000 & 0.01 & 13722 \\
Time-to-Maturity & 5.1315 & 5.1808 & 17.1973 & 1.0685 & 1.6668 & 4235.8130 & 0.01 & 13722 \\
Age & 2.1097 & 1.8603 & 12.5890 & 0.0932 & 1.3961 & 5600.3490 & 0.01 & 13722 \\
Coupon & 7.0229 & 7.0000 & 9.1000 & 3.5000 & 0.9200 & 259.2570 & 0.01 & 13722 \\
Rating & 3.4575 & 4.0000 & 15.0000 & 1.0000 & 1.2309 & 219525.1000 & 0.01 & 13722 \\
\hline
\end{tabular}

Spread is the difference between the yield-to-maturity on the corporate bond and the corresponding Treasury rate. Turnover is the frequency of market assets traded in a certain period of time, and the calculation method is the ratio of the trading volume and the circulation market value. Vol is the average of the total trading volume (yuan), and Day is the number of trading days in the corresponding month. Amihud and Range are illiquidity measures. Time-to-Maturity denotes the remaining years of the bond. Age denotes years since issuance. Coupon is the annual coupon interest. Rating is the credit rating of each bond. The sample period is July 2006 to June 2016, and the sample includes 1224 bonds.

TABLE 2: Pairwise correlations between liquidity proxies.

\begin{tabular}{|c|c|c|c|c|c|}
\hline & Turnover & Vol & Day & Amihud & Range \\
\hline \multicolumn{6}{|c|}{ Panel A: liquidity proxies } \\
\hline Turnover & 1.0000 & & & & \\
\hline Vol & 0.8724 & 1.0000 & & & \\
\hline Day & 0.0238 & 0.0249 & 1.0000 & & \\
\hline Amihud & -0.0880 & -0.0925 & -0.0344 & 1.0000 & \\
\hline \multirow[t]{2}{*}{ Range } & -0.0941 & -0.0989 & -0.0172 & 0.8343 & 1.0000 \\
\hline & Turnover_diff & Vol_diff & Day_diff & Amihud_diff & Range_diff \\
\hline \multicolumn{6}{|c|}{ Panel B: differences in liquidity measures } \\
\hline Turnover_diff & 1.0000 & & & & \\
\hline Vol_diff & 0.8661 & 1.0000 & & & \\
\hline Day_diff & 0.2082 & 0.2555 & 1.0000 & & \\
\hline Amihud_diff & -0.1425 & -0.1052 & -0.1270 & 1.0000 & \\
\hline Range_diff & -0.1205 & -0.0862 & -0.1096 & 0.8307 & 1.0000 \\
\hline
\end{tabular}

For Panel A, the meanings of liquidity proxies are shown in Table 1. For Panel B, the variables are the differences between the exchange market and the interbank market for the corresponding variables of individual bonds. The sample period is July 2006 to June 2016; the sample includes 1224 bonds.

TABLE 3: Summary statistics of differences in liquidity measures.

\begin{tabular}{|c|c|c|c|c|c|c|c|c|}
\hline Variable & Mean & Median & Maximum & Minimum & Std. dev. & Jarque-Bera & Probability & Observations \\
\hline \multicolumn{9}{|c|}{ Panel A: all bonds } \\
\hline Turnover_diff & -0.0972 & -0.0568 & 0.6881 & -2.1164 & 0.1529 & 164007.4000 & 0.01 & 6784 \\
\hline Vol_diff & -106.2037 & -63.5312 & 527.2476 & -2808.4630 & 158.4403 & 283567.2000 & 0.01 & 6784 \\
\hline Day_diff & 4.9148 & 2.0000 & 22.0000 & -12.0000 & 6.4997 & 964.8958 & 0.01 & 6784 \\
\hline Amihud_diff & 0.0294 & 0.0012 & 3.5206 & -0.2771 & 0.1424 & 13802006.0000 & 0.01 & 6784 \\
\hline Range_diff & 0.0498 & 0.0025 & 5.6514 & -0.1763 & 0.2239 & 14038398.0000 & 0.01 & 6784 \\
\hline \multicolumn{9}{|c|}{ Panel $B$ : high rating bonds } \\
\hline Turnover_diff & -0.0749 & -0.0435 & 0.3059 & -1.4227 & 0.1211 & 44359.4900 & 0.01 & 2185 \\
\hline Vol_diff & -96.0034 & -57.8675 & 392.7113 & -2808.4630 & 148.9268 & 318762.9000 & 0.01 & 2185 \\
\hline Day_diff & 4.6691 & 2.0000 & 22.0000 & -11.0000 & 6.2821 & 392.0431 & 0.01 & 2185 \\
\hline Amihud_diff & 0.0239 & 0.0009 & 3.3447 & -0.0378 & 0.1382 & 7660864.0000 & 0.01 & 2185 \\
\hline Range_diff & 0.0430 & 0.0018 & 4.8422 & -0.0393 & 0.2170 & 5477773.0000 & 0.01 & 2185 \\
\hline \multicolumn{9}{|c|}{ Panel C: low rating bonds } \\
\hline Turnover_diff & -0.1079 & -0.0648 & 0.6881 & -2.1164 & 0.1649 & 97938.2000 & 0.01 & 4599 \\
\hline Vol_diff & -111.0498 & -67.0638 & 527.2476 & -2526.0090 & 162.5571 & 96771.0800 & 0.01 & 4599 \\
\hline Day_diff & 5.0315 & 3.0000 & 22.0000 & -12.0000 & 6.5980 & 592.4450 & 0.01 & 4599 \\
\hline Amihud_diff & 0.0320 & 0.0015 & 3.5206 & -0.2771 & 0.1443 & 7172313.0000 & 0.01 & 4599 \\
\hline Range_diff & 0.0530 & 0.0028 & 5.6514 & -0.1763 & 0.2270 & 8748478.0000 & 0.01 & 4599 \\
\hline
\end{tabular}

The table shows the summary statistics for variables used in the study. The meanings of liquidity proxies are shown in Tables 1 and 2 . The sample period is July 2006 to June 2016. 
TABLE 4: Marginal impact of liquidity proxies on bond spreads.

\begin{tabular}{lcccccc}
\hline & Vol & Day & Range & Vol $\times$ coupon & Day $\times$ coupon & Range $\times$ coupon \\
\hline \multirow{2}{*}{ High rating } & $-0.0022^{* * *}$ & $0.0809^{* * *}$ & -0.1267 & $0.0003^{* * *}$ & $-0.0045^{*}$ & 0.0387 \\
& $(-3.06)$ & $(4.51)$ & $(-0.26)$ & $(2.93)$ & $(-1.82)$ & $(0.52)$ \\
Low rating & $-0.0015^{* *}$ & $0.2109^{* * *}$ & $1.4225^{* *}$ & $0.0002^{*}$ & $-0.0197^{* * *}$ & $-0.1700^{* *}$ \\
& $(-1.98)$ & $(11.55)$ & $(2.26)$ & $(1.83)$ & $(-8.06)$ & $(-1.97)$ \\
Full sample & $-0.0018^{* * *}$ & $0.1596^{* * *}$ & 0.5125 & $0.0002^{* * *}$ & $-0.0132^{* * *}$ & -0.0461 \\
& $(-3.41)$ & $(12.03)$ & $(1.34)$ & $(3.02)$ & $(-7.37)$ & $(-0.85)$ \\
\hline
\end{tabular}

The table shows the marginal impact of liquidity proxies on bond spreads, for the full sample, the subsample of high rating bonds, and the subsample of low rating bonds. Bond spreads are regressed directly on each liquidity proxy by controlling credit risk and interaction. The meanings of liquidity proxies are shown in Tables 1 and 2 . The cross-terms are interactions. The sample period is July 2006 to June 2016. The $t$-statistics are given in parentheses, and *, ${ }^{* *}$, and *** represent significance at the $10 \%, 5 \%$, and $1 \%$ level, respectively.

TABLE 5: Marginal impact of liquidity proxies on the nondefault spread based on equation (1).

\begin{tabular}{|c|c|c|c|c|c|c|}
\hline & Vol_diff & Day_diff & Range_diff & Vol_diff $\times$ coupon & Day_diff $\times$ coupon & Range_diff $\times$ coupon \\
\hline High rating & $\begin{array}{c}-0.0010^{* *} \\
(-2.15)\end{array}$ & $\begin{array}{c}0.0529^{* * *} \\
(4.75)\end{array}$ & $\begin{array}{c}0.1678 \\
(0.52)\end{array}$ & $\begin{array}{c}0.0001^{* *} \\
(2.11)\end{array}$ & $\begin{array}{c}-0.0075^{* * *} \\
(-4.92)\end{array}$ & $\begin{array}{c}-0.0149 \\
(-0.30)\end{array}$ \\
\hline Low rating & $\begin{array}{c}-0.0014^{* *} \\
(-2.36)\end{array}$ & $\begin{array}{c}0.0764^{* * *} \\
\quad(5.28)\end{array}$ & $\begin{array}{l}0.4507 \\
(0.87)\end{array}$ & $\begin{array}{c}0.0002^{* *} \\
(2.07)\end{array}$ & $\begin{array}{c}-0.0099^{* * *} \\
(-5.21)\end{array}$ & $\begin{array}{c}-0.0473 \\
(-0.66)\end{array}$ \\
\hline Full sample & $\begin{array}{c}-0.0012^{* * *} \\
(-2.93)\end{array}$ & $\begin{array}{c}0.0647^{* * *} \\
\quad(6.71)\end{array}$ & $\begin{array}{c}0.2682 \\
(0.91)\end{array}$ & $\begin{array}{c}0.0001^{* * *} \\
(2.62)\end{array}$ & $\begin{array}{c}-0.0086^{* * *} \\
(-6.71)\end{array}$ & $\begin{array}{l}-0.025 \\
(-0.60)\end{array}$ \\
\hline $\operatorname{Adj}-R^{2}(\%)$ & 0.2387 & 0.7718 & 0.1243 & 0.2406 & 0.7978 & 0.1445 \\
\hline
\end{tabular}

The table shows the marginal impact of liquidity proxies on the nondefault spread based on equation (1), for the full sample, the subsample of high rating bonds, and the subsample of low rating bonds. The nondefault spread is regressed directly on each liquidity proxy by controlling interaction. The adjusted Rsquares for the full sample are reported. The meanings of liquidity proxies are shown in Tables 1 and 2 . The cross-terms are interactions. The sample period is July 2006 to June 2016 . The $t$-statistics are given in parentheses, and ${ }^{*},{ }^{* *}$, and ${ }^{* * *}$ represent significance at the $10 \%, 5 \%$, and $1 \%$ level, respectively.

Tables 4 and 5 while it declines from 0.2109 to 0.0764 in the low rating ones. The coefficient of Range is significant at the level of $5 \%$ in the low rating bonds in Table 4 . According to the empirical results, there is a significant correlation between the nondefault spread and the interaction between liquidity and credit risk. For example, the coefficients of Vol_diff $\times$ Coupon and Day_diff $\times$ Coupon are significant at the level of $1 \%$ in the full sample in Table 5. In conclusion, our empirical results confirm that the interaction between liquidity and credit risk is priced in China's corporate bond market.

As Tables 4 and 5 show, only a small part of the nondefault spread is explained by liquidity proxies, and the interaction between liquidity and credit risk is significantly priced. To investigate these results thoroughly, the related regression results are given in Tables 6 and 7. Regression results without the interaction between liquidity and credit risk are shown in Model 1 of Tables 6 and 7. The regression result of Model 1 in Table 6 shows that the regression coefficient of $\mathrm{Vol}$ is significant at the level of $1 \%$, and the sign is in line with expectations, while the regression coefficient of Range is very significant. The regression result of Model 1 in Table 7 gives the impact of liquidity differences on the nondefault spread without considering interaction. It shows that the regression coefficient of Vol_diff is significant at the level of $1 \%$, while the regression coefficient of Range_diff is significant at the level of $10 \%$. In addition, Adj- $R^{2}$ of Model 1 in Table 6 is $19.4355 \%$, while Adj- $R^{2}$ of Model 1 in Table 7 is only $0.1540 \%$, which shows that a small part of the nondefault spread is explained by liquidity proxies.
The interaction between liquidity and credit risk is considered to examine whether the interaction is priced. In Model 2 of Table 6 , the coefficient of $\mathrm{Vol} \times \mathrm{Coupon}$ is very significant, and Adj- $R^{2}$ is $19.4831 \%$, which is higher than $19.4355 \%$ of Model 1 in Table 6. In Model 2 of Table 7, the significance of the coefficient of Vol_diff $\times$ Coupon is $1 \%$, and $\mathrm{Adj}-R^{2}$ is $0.2406 \%$, which is higher than $0.1540 \%$ of Model 1 in Table 7 . This shows that the interaction between liquidity and credit risk is significantly priced. The reason is that both liquidity and credit risk are closely related to market factors and macrofactors, and when market conditions change, liquidity and credit risk must comove and induce interaction. Adj- $R^{2}$ of Model 2 in Table 6 is much larger than that of Model 2 in Table 7, which indicates that liquidity proxies explain only a small fraction of the nondefault spread. Similar conclusions are obtained in Model 3 of Tables 6 and 7.

Overall, the empirical research in Tables 6 and 7 shows that after the nondefault spread is extracted and interaction is considered, only a small part of the nondefault spread is explained by liquidity proxies, and the nondefault spread may be affected by other important factors.

5.3. Impact of Bond Market Liquidity and Stock Market Liquidity on Spreads. The impact of market liquidity on spreads cannot be ignored, because there is a systematic liquidity factor. Market liquidity affects the nondefault spread by the systematic liquidity factor.

Bond market liquidity and stock market liquidity are taken into account as market liquidity factors. This study 
TABLE 6: Impact of liquidity proxies on bond spreads for the full sample.

\begin{tabular}{|c|c|c|c|c|c|c|c|c|}
\hline Model & $C$ & Vol & Day & Range & Vol $\times$ coupon & Day $\times$ coupon & Range $\times$ coupon & $\operatorname{Adj}-R^{2}(\%)$ \\
\hline 1 & $\begin{array}{c}-0.1002 \\
(-1.49)\end{array}$ & $\begin{array}{c}-0.0003^{* * *} \\
(-3.54)\end{array}$ & $\begin{array}{c}0.0633^{* * *} \\
(32.38)\end{array}$ & $\begin{array}{c}0.1523^{* * *} \\
(2.77)\end{array}$ & & & & 19.4355 \\
\hline 2 & $\begin{array}{c}0.0268 \\
(0.34)\end{array}$ & $\begin{array}{c}-0.0019^{* * *} \\
(-3.51)\end{array}$ & $\begin{array}{c}0.0636^{* * *} \\
(32.50)\end{array}$ & $\begin{array}{c}0.1530^{* * *} \\
(2.79)\end{array}$ & $\begin{array}{c}0.0002^{* * *} \\
(3.02)\end{array}$ & & & 19.4831 \\
\hline 3 & $\begin{array}{c}-0.5341^{* * *} \\
(-5.97)\end{array}$ & $\begin{array}{c}-0.0003^{* * *} \\
(-3.76)\end{array}$ & $\begin{array}{c}0.1600^{* * *} \\
(12.06)\end{array}$ & $\begin{array}{c}0.1429^{* * *} \\
(2.60)\end{array}$ & & $\begin{array}{c}-0.0132^{* * *} \\
(-7.37)\end{array}$ & & 19.7471 \\
\hline 4 & $\begin{array}{c}-0.1094 \\
(-1.60)\end{array}$ & $\begin{array}{c}-0.0003^{* * *} \\
(-3.55)\end{array}$ & $\begin{array}{c}0.0632^{* * *} \\
(32.31)\end{array}$ & $\begin{array}{l}0.4717 \\
(1.24)\end{array}$ & & & $\begin{array}{c}-0.0461 \\
(-0.85)\end{array}$ & 19.4338 \\
\hline 5 & $\begin{array}{c}-0.4169^{* * *} \\
(-4.16)\end{array}$ & $\begin{array}{c}-0.0018^{* * *} \\
(-3.39)\end{array}$ & $\begin{array}{c}0.1598^{* * *} \\
(12.05)\end{array}$ & $\begin{array}{l}0.3451 \\
(0.90)\end{array}$ & $\begin{array}{c}0.0002^{* * *} \\
(2.87)\end{array}$ & $\begin{array}{c}-0.0132^{* * *} \\
(-7.34)\end{array}$ & $\begin{array}{l}-0.029 \\
(-0.53)\end{array}$ & 19.7878 \\
\hline
\end{tabular}

The table shows the impact of liquidity proxies on bond spreads for the full sample, and bond spreads are regressed on the liquidity proxies by controlling credit risk and interaction. The meanings of liquidity proxies are shown in Tables 1 and 2 . The interaction between liquidity and credit risk is represented by the cross-terms. The sample period is July 2006 to June 2016. The $t$-statistics are given in parentheses, and ${ }^{*},{ }^{* *}$, and ${ }^{* * *}$ represent significance at the $10 \%, 5 \%$, and $1 \%$ level, respectively.

TABLE 7: Impact of liquidity proxies on the nondefault spread for the full sample based on equation (1).

\begin{tabular}{|c|c|c|c|c|c|c|c|c|}
\hline Model & $C$ & Vol_diff & Day_diff & Range_diff & Vol_diff $\times$ coupon & Day_diff $\times$ coupon & Range_diff $\times$ coupon & $\operatorname{Adj}-R^{2}(\%)$ \\
\hline 1 & $\begin{array}{c}0.1166^{* * *} \\
\quad(7.77)\end{array}$ & $\begin{array}{c}-0.0002^{* * *} \\
(-2.95)\end{array}$ & $\begin{array}{c}0.0003 \\
(0.21)\end{array}$ & $\begin{array}{c}0.0804^{*} \\
(1.86)\end{array}$ & & & & 0.1540 \\
\hline 2 & $\begin{array}{c}0.1214^{* * *} \\
(8.04)\end{array}$ & $\begin{array}{c}-0.0012^{* * *} \\
(-3.06)\end{array}$ & $\begin{array}{c}0.0008 \\
(0.50)\end{array}$ & $\begin{array}{c}0.0824^{*} \\
(1.91)\end{array}$ & $\begin{array}{c}0.0001^{* * *} \\
(2.62)\end{array}$ & & & 0.2406 \\
\hline 3 & $\begin{array}{c}0.1248^{* * *} \\
\quad(8.32)\end{array}$ & $\begin{array}{c}-0.0002^{* * *} \\
(-3.37)\end{array}$ & $\begin{array}{c}0.0639^{* * *} \\
\quad(6.66)\end{array}$ & $\begin{array}{c}0.0752^{*} \\
(1.74)\end{array}$ & & $\begin{array}{c}-0.0086^{* * *} \\
(-6.71)\end{array}$ & & 0.7978 \\
\hline 4 & $\begin{array}{c}0.1165^{* * *} \\
\quad(7.77)\end{array}$ & $\begin{array}{c}-0.0002^{* * *} \\
(-2.97)\end{array}$ & $\begin{array}{c}0.0003 \\
(0.20)\end{array}$ & $\begin{array}{l}0.2541 \\
(0.86)\end{array}$ & & & $\begin{array}{l}-0.025 \\
(-0.60)\end{array}$ & 0.1445 \\
\hline 5 & $\begin{array}{c}0.1270^{* * * *} \\
(8.41)\end{array}$ & $\begin{array}{c}-0.0007^{*} \\
(-1.82)\end{array}$ & $\begin{array}{c}0.0616^{* * *} \\
(6.31)\end{array}$ & $\begin{array}{l}0.0416 \\
(0.14)\end{array}$ & $\begin{array}{l}0.0001 \\
(1.32)\end{array}$ & $\begin{array}{c}-0.0082^{* * *} \\
(-6.31)\end{array}$ & $\begin{array}{l}0.005 \\
(0.12)\end{array}$ & 0.7942 \\
\hline
\end{tabular}

The table shows the impact of liquidity proxies on the nondefault spread for the full sample based on equation (1). The nondefault spread is regressed on the liquidity proxies by controlling credit risk and interaction. The meanings of liquidity proxies are shown in Tables 1 and 2 . The interaction between liquidity and credit risk is represented by the cross-terms. The sample period is July 2006 to June 2016 . The $t$-statistics are given in parentheses, and ${ }^{*},{ }^{* *}$, and ${ }^{* * *}$ represent significance at the $10 \%, 5 \%$, and $1 \%$ level, respectively.

chooses the liquidity proxies of bond market from two perspectives, transaction activity and price impact, including BML_Vol, BML_Range, and BML_Amihud to investigate the explanatory power of bond market-level liquidity on spreads. BML_Vol is the monthly trading volume of the corporate bond market. BML_Range and BML_Amihud are illiquidity measures of the corporate bond market based on Range and Amihud, respectively.

Table 8 presents the empirical results. Vol_diff and Range_diff are liquidity differences, and they represent the transaction activity and price impact. Models $1-3$ give the basic regression models. Adj- $R^{2}$ of the regression equation in Model 3 is $0.1681 \%$. In Models $4-6$, the market liquidity proxies are introduced to investigate the impact of market factors on the nondefault spread. In Model 4, the regression coefficient of BML_Vol is significant at the level of $1 \%$, and Adj- $R^{2}$ of the regression equation increases from $0.1681 \%$ to $0.8264 \%$ when the proxy of bond market liquidity is considered. This suggests that bond market liquidity significantly improves the explanatory power of the nondefault spread and is priced. As proxies for liquidity, BML_Vol represents trading activity, while BML_Range and BML_Amihud represent price impact. In Model 6, the regression coefficient of BML_Amihud is significant at the level of $1 \%$, and $\mathrm{Adj}-R^{2}$ of the regression equation increases from $0.1681 \%$ to $0.3251 \%$. This conclusion is similar to that of Model 4.

Considering the spillover and linkage effects between the bond market and stock market, the liquidity of the stock market is used to explain the nondefault spread in Model 7. Vol_diff and Range_diff are used as liquidity proxies, and SML_Range is an illiquidity measure of stock market based on Range. The Adj- $R^{2}$ of Model 7 is $0.8503 \%$ and increases more than that of Model 3. Similar conclusions are found in Models 8-10. This shows that stock market information can significantly explain the nondefault spread, and the stock market has liquidity spillover effects on the bond market. Similar results are obtained by Chordia et al. [9] and Goyenko and Ukhov [10]. Model 11 shows the regression results containing all liquidity and market liquidity proxies. The coefficient of Vol_diff is significant at the level of $1 \%$, and the signs are in line with expectations. The coefficients of BML_Vol and SML_Range are all significant at the level of $1 \%$, and the Adj- $R^{2}$ of Model 11 is $1.2797 \%$. We find that the price difference of the two markets for the same bond is significantly related to stock market liquidity. 


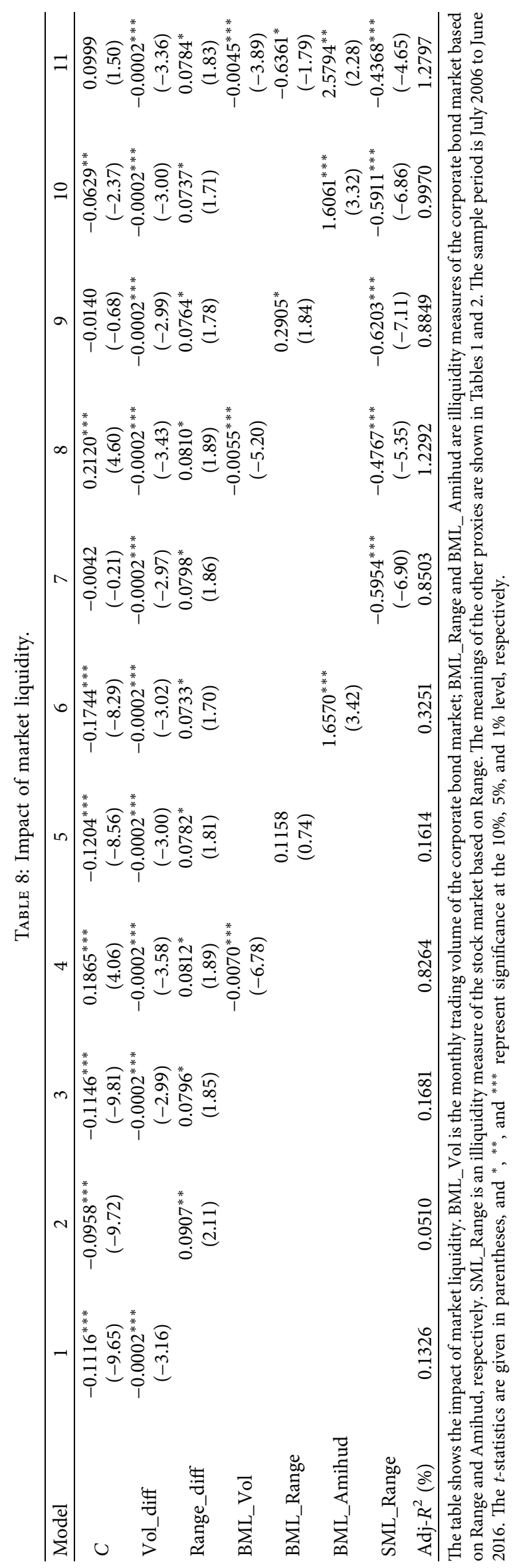


5.4. Impact of Macrofactors on Spreads. Table 9 presents the regression results.

Model 2 considers bond market and stock market liquidity. The coefficients of BML_Vol and SML_Range are significant at the level of $1 \%$, and $\mathrm{Adj}-R^{2}$ of Model 1 is $1.354 \%$. The regression coefficient of BML_Vol is negative, because bond market liquidity is good and the liquidity premium is small. However, the regression coefficient of SML_Range is negative because of spillover effects between the stock market and bond market. In other words, when stock market liquidity is poor, bond market liquidity is good, and thus, the premium of bond market liquidity is small.

Models 2-7 consider macrovariables to investigate the impact of macrofactors on the price difference of the two markets for the same bond. The following three macrovariables are selected: Year102, Month3, and S10year. Year102 is the difference between the 10-year Treasury rate and the 2-year Treasury rate. Month3 is the 3-month Treasury rate, and S10year is the spread between the bond market index yield and the 10-year Treasury rate. In Models 2-4, the coefficients of Year102, Month3, and S10year are $0.1141,-0.0907$, and 0.1276 , respectively, at a significance level of $1 \%$, while Adj- $R^{2}$ of Model 4 is significantly improved compared with Model 1. This shows that macrofactors have good explanatory power for the price difference of the two markets for the same bond. Similar conclusions are obtained in Models 5-7. CPI, which is the consumer price index, is used to explain the nondefault spread as the proxy of macrofactor; the coefficients of CPI are all significant at the 1\% level in Models 8-12. This shows that CPI can explain the nondefault spread well, and macrofactors are the explanatory variables of the nondefault spread. GDP is a good proxy of macrofactors; the empirical results of Model 6 show that the coefficient of GDP is very significant, and Adj$R^{2}$ is also improved compared with Model 1 . The circulation of currency, represented by $M_{0}$, is an important macrovariable. The empirical result of Model 7 shows that the coefficient of $M_{0}$ is very significant, and Adj- $R^{2}$ is $1.5476 \%$.

In Model 8, all macrofactors are considered to investigate the impact of macrofactors on spreads. Macrofactors and market factors are all considered in Model 9. In this model, the regression coefficient of Range_diff is not significant, which means that the nondefault spread is not sensitive to illiquidity proxy using extreme values in China's corporate bond market. Range_diff is replaced by Amihud_diff in Models 10-12, and the coefficients of Amihud_diff are very significant. In Model 9, the coefficient of SML_Range is not significant; a similar result is obtained from Model 10. In Model 11, the coefficient of Range_diff is significant at the level of $10 \%$. Because the macrofactors contain stock market information, better liquidity in the stock market will result from, for example, loose monetary policy. In addition, the interaction between liquidity and credit risk is represented by the cross-terms in Models 1-12.

Because macrofactors contain stock market information, SML_Range is removed, and the regression result is given in Model 12 . Adj- $R^{2}$ of Model 12 is $2.8771 \%$, and is slightly improved, while Adj- $R^{2}$ of Model 12 is 17.12 times bigger than that of Model 1, which indicates that the proxies of liquidity explain only a small part of the nondefault spread, and the nondefault spread is also affected by the unknown factors. In other words, a systematic liquidity factor exists, and it affects the liquidity of individual bonds in the bond market.

These empirical results show that market liquidity risk and macro risk factors are the main determinants of the price difference of the two markets for the same bond.

\section{Robustness Tests}

6.1. Price Impact. To investigate the robustness of our results, a series of robustness tests are performed. Range is replaced by Amihud to investigate the impact of liquidity proxy on the price difference of the two markets for the same bond from the perspective of price impact in Table 10.

In Model 1 , the coefficient of $\mathrm{Vol}$ is -0.0002 and is significant at the level of $1 \%$, while the regression coefficient of Amihud is also significant at the level of $1 \%$, and the sign is in line with expectations. In Model 2, the coefficient of BML_Vol is significant at the level of $1 \%$, and Adj- $R^{2}$ is improved 3.6 times compared with Model 1, which indicates that market liquidity has explanatory power for the nondefault spread. In Model 3, the coefficients of Year102 and S10year are 0.1389 and 0.1521 and are significant at the level of $1 \%$, while the coefficients of Year102, S10year, CPI, GDP, and $M_{0}$ are also significant at the level of $1 \%$ in Model 4 . In addition, Adj- $R^{2}$ of Models 3 and 4 is $1.9262 \%$ and $2.7850 \%$, respectively and is significantly improved over that of Model 1 , which indicates that macrofactors are significant explanatory variables for the nondefault spread, and our empirical results are robust in the Chinese corporate bond market.

Model 5 shows the empirical results including the interaction between liquidity and credit risk. The coefficient of Vol $\times$ Coupon is 0.0002 and is significant at the level of $1 \%$, while the coefficient of Day $\times$ Coupon is also significant at the level of $5 \%$. Adj- $R^{2}$ of Model 5 is greater than that of Model 4, suggesting that the interaction between liquidity and credit risk is significantly priced in the Chinese corporate bond market. In addition, the empirical results of Models 1-5 show that the coefficients of Amihud_diff are all very significant in the Chinese corporate bond market.

6.2. Trading Activity. Trading activity is an important aspect of liquidity, and Turnover is a commonly used measure of liquidity. To investigate the robustness of our results, Vol_diff is replaced by Turnover_diff to investigate the impact of liquidity proxy on the price difference of the two markets for the same bond from the perspective of trading activity in Table 11.

The empirical results of Models 1-5 show that the coefficients of Turnover_diff are all significant at the level of $1 \%$, and the sign is in line with expectations. Adj- $R^{2}$ of Model 1 is $0.2989 \%$, while Adj- $R^{2}$ of Model 2 is $0.9703 \%$, and the coefficient of BML_Vol is significant at the level of $1 \%$. This indicates that market liquidity has good explanatory power for the nondefault spread, and this result is robust. In Model 


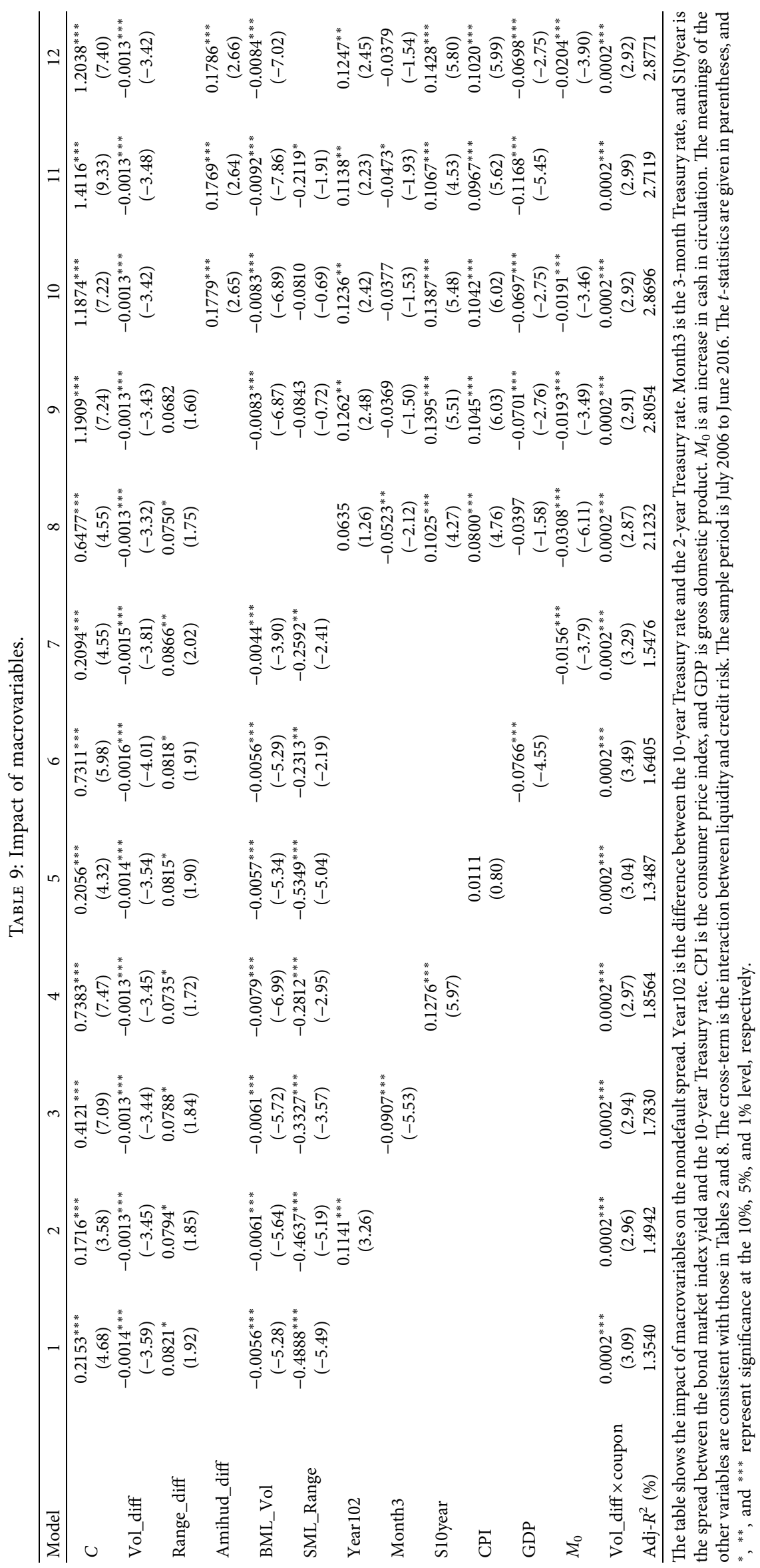




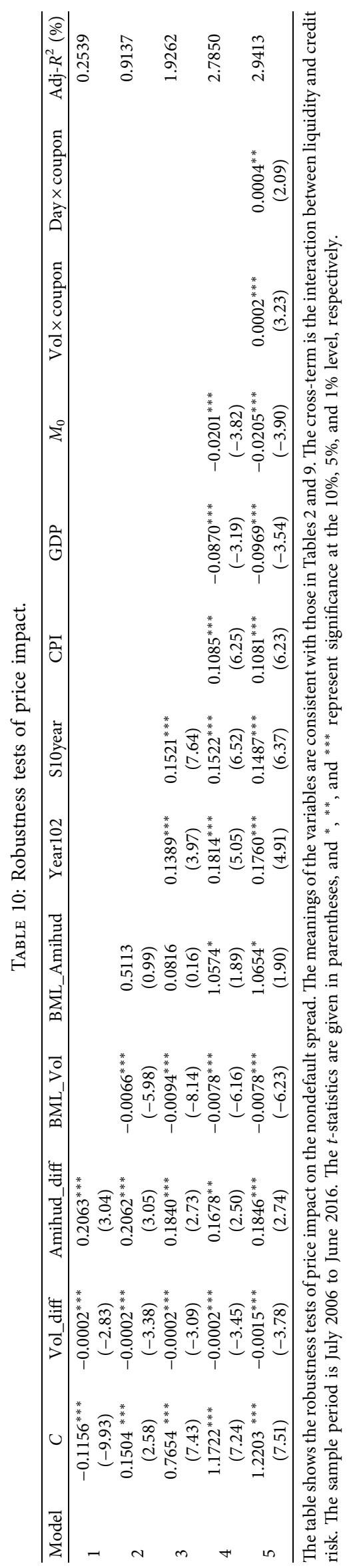




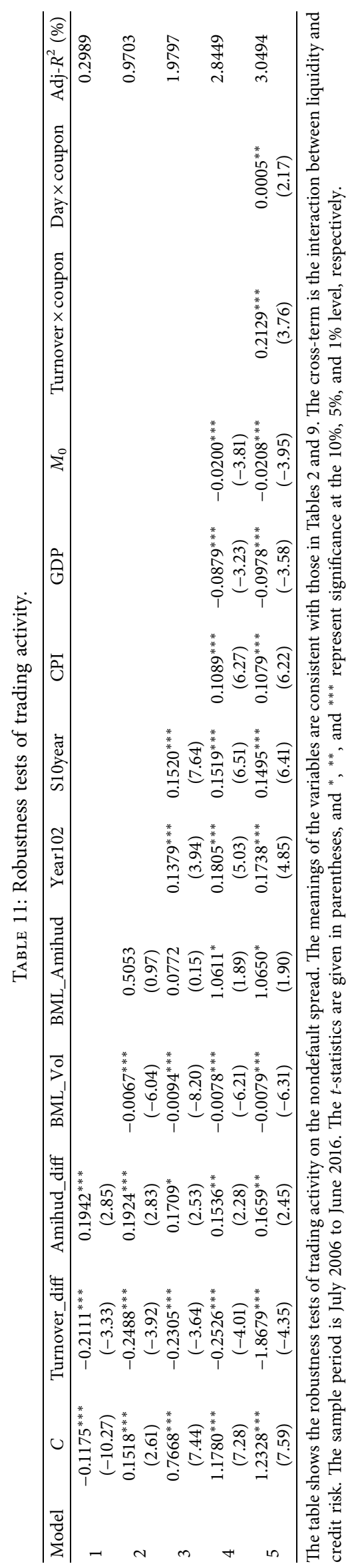


3, the coefficients of Year102 and S10year are 0.1379 and 0.1520 and are significant at the level of $1 \%$, while the coefficients of Year102, S10year, CPI, GDP, and $M_{0}$ are also significant at the level of $1 \%$ in Model 4 . In addition, Adj- $R^{2}$ of Models 3 and 4 are $1.9797 \%$ and $2.8449 \%$ and are significantly improved compared with Model 1, which indicates that macrofactors are significant explanatory variables for the nondefault spread, and our empirical results are robust. The interaction between liquidity and credit risk is considered in Table 11 in order to investigate whether it is priced. Similar results are obtained to those in Model 5. The coefficient of Turnover $\times$ Coupon is 0.2129 and is significant at the level of $1 \%$, while the coefficient of Day $\times$ Coupon is also significant at the level of $5 \%$; Adj- $\mathrm{R}^{2}$ of Model 5 is $3.0494 \%$ and is greater than that of Model 4. This suggests that the interaction between liquidity and credit risk is significantly priced in the Chinese corporate bond market. In addition, the empirical results of Models 1-5 show that the coefficients of Amihud_diff are all very significant. The empirical results of Table 11 show that our results are robust.

6.3. Subsamples. The robustness test results for subsamples are given in Table 12. In Panel A, the empirical results of the high credit rating subsample show that the coefficients of Turnover_diff, BML_Vol, S10year, CPI, GDP, and Turnover $\times$ Coupon are all significant at the level of $1 \%$. This shows that market liquidity and macrofactors have explanatory power for the price difference of the two markets for the same bond and the interaction is significantly priced in the Chinese corporate bond market. In addition, the coefficient of BML_Amihud is significant at the level of 5\% in the subsample of low credit rating, while the coefficient is at the level of $10 \%$ in the subsample of high credit rating, which shows that the nondefault spread of low credit rating bonds is more susceptible to market factors than that of high credit rating bonds. The coefficients of Year102 and $M_{0}$ are significant at the level of $1 \%$ in the subsample of low credit rating, while their coefficients are significant at the level of $5 \%$ in the subsample of high credit rating, which shows that the nondefault spread of low credit rating bonds is more susceptible to macrofactors than that of high credit rating bonds.

In Panel B of Table 12, the sample is divided into two parts associated with coupon. Similar results are obtained in Panel B. The empirical results of the high coupon subsample show that the coefficients of BML_Vol, Year102, S10year, CPI, GDP, and Turnover $\times$ Coupon are all significant at the level of $1 \%$, while the empirical results of the low coupon subsample show that the coefficients of BML_Vol, Year102, S10year, CPI, and Day $\times$ Coupon are all significant at the level of $1 \%$. This shows that market liquidity and macrofactors have explanatory power for the nondefault spread and interaction is significantly priced. In addition, the coefficient of BML_Amihud is significant at the level of 5\% in the high coupon subsample, while the coefficient is at the level of $10 \%$ in the low coupon subsample, which shows that the nondefault spread of high coupon bonds is more susceptible to market factors than that of low coupon bonds.
In Panel C of Table 12, the sample is divided into two parts associated with age. The coefficients of BML_Amihud, S10year, CPI, and $M_{0}$ are not significant in the high age subsample, while their coefficients are significant at the level of $1 \%$ in the low age subsample. The reason for this is that bonds of high age are often held as asset allocation, and thus, they are less affected by macrofactors, while bonds of low age are more active and are sensitive to macrofactors. The coefficient of Day $\times$ Coupon is not significant, and the coefficient of Turnover $\times$ Coupon is significant at the level of $5 \%$ in the high age subsample, while their coefficients are significant at the level of $1 \%$ in the low age subsample. This shows that bonds of low age are sensitive to interaction.

In addition, Adj- $R^{2}$ of the subsamples is high, ranging from $1.7487 \%$ to $6.2333 \%$, and is far higher than that considering liquidity proxies. This shows that our results are robust. Only a small part of the nondefault spread is explained by liquidity proxies, and market liquidity and macrofactors have good explanatory power for the price difference of the two markets for the same bond for the following reasons. There is a systematic liquidity factor, and it affects the liquidity of individual bonds in the bond market. Macrofactors and stock market liquidity affect the nondefault spread by affecting the systematic liquidity factor of the bond market.

In Panel A of Table 12, the coefficients of Turnover $\times$ Coupon are 0.2361 and 0.2009 and are significant at the level of $1 \%$ for the high credit rating and low credit rating subsamples. In Panel B, the coefficient of Turnover $\times$ Coupon is 0.3689 and is significant at the level of $1 \%$ in the high coupon subsample, while the coefficient of Day $\times$ Coupon is also significant at the level of $1 \%$ in the low coupon subsample. In Panel C, the coefficient of Turnover $\times$ Coupon is 0.2434 and is significant at the level of $5 \%$ in the high age subsample, while the coefficients of Turnover $\times$ Coupon and Day $\times$ Coupon are also significant at the level of $1 \%$ in the low age subsample. This shows that the interaction between liquidity and credit risk is significantly priced and has good explanatory power for the price difference of the two markets for the same bond, and our results are robust in China's corporate bond market. The reason is that although liquidity and credit risk are two different types of risk, they mutually influence each other. Ericsson and Renault [52] find that liquidity and credit risk are correlated and when market liquidity is poor, credit risk of bonds is large, which suggests that there liquidity and credit risk interact. We find that the price difference of the two markets for the same bond is significantly related to the interaction between liquidity and credit risk.

\section{Interaction between Liquidity and Credit Risk during the Financial Crisis}

7.1. Temporal Characteristics of Average Spreads. We study the temporal characteristics of the monthly average spreads in the Chinese corporate bond market, namely, the interbank market and the exchange market. The characteristics of average spreads are very similar, probably because they are subject to common systematic risk. From May 2007 to 


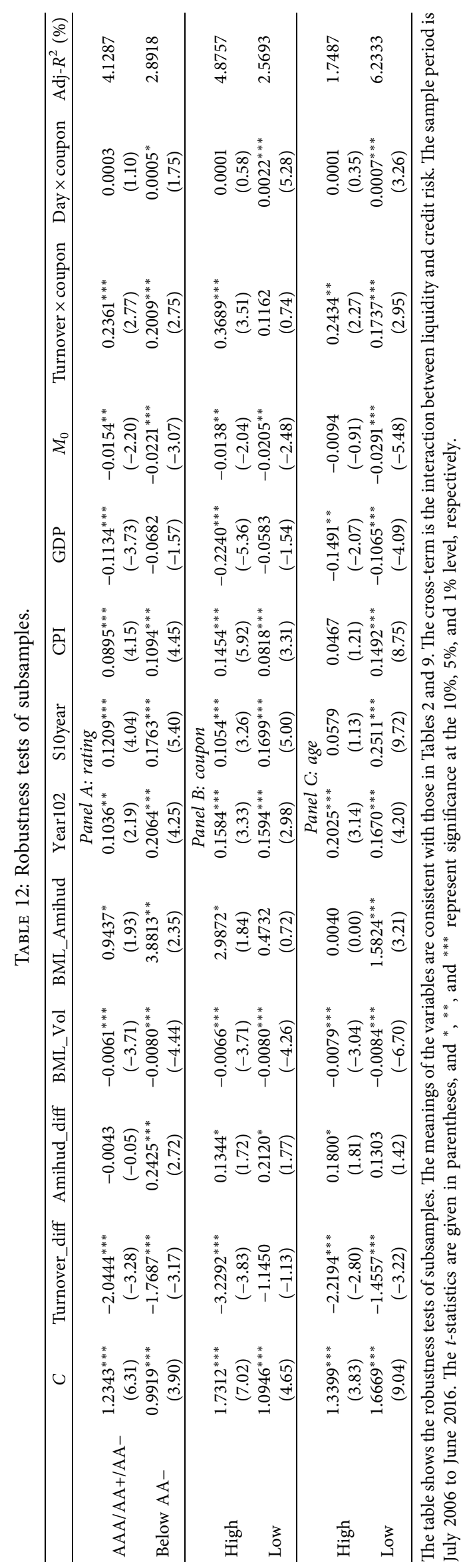


January 2010, the average spreads gradually increase and reach the maximum value in March 2012. Then, the average spreads gradually decrease. The main reason that the spreads increase from May 2007 to January 2010 is the outbreak of the global financial crisis, leading investors to demand a higher premium for compensation. From October 2010 to March 2012, the liquidity of China's financial market is small, and liquidity risk is increasing; thus, the spreads gradually increase. Since April 2012, China has carried out a series of financial reforms, and liquidity has gradually improved; market liquidity tends toward stability, and thus, the spreads slowly become smaller.

Based on the above analysis and Dick-Nielsen et al. [1], we divide the period from July 2006 to June 2016 into two: the period of financial crisis from May 2007 to December 2009 , and the normal period on either side of it.

\subsection{Impact of Interaction between Liquidity and Credit Risk on} Spreads. We choose the basic liquidity and credit risk proxies and use their cross-terms to represent the interaction. To study the impact of the interaction on spreads, we divide the sample into the financial crisis period and the normal period. The relevant empirical results are shown in Tables 13 and 14.

The regression results containing the interaction are given in Table 13 and those containing only liquidity and credit risk are given in Table 14. Both in the normal period and during the financial crisis, the $\mathrm{Adj}-R^{2}$ of the regression models with the interaction significantly increases. For example, the increase of Adj- $R^{2}$ was the largest (from 0.4797 to 0.5389 ) in the exchange market during the financial crisis period. In addition, some variables are significant because interaction variables are considered. The $t$-statistic of Amihud increases from -0.18 to 2.36 owing to the consideration of interaction in the interbank market during the financial crisis. This suggests that the interaction between liquidity and credit risk is an essential explanatory variable for the spreads. We now turn to the empirical results considering the interaction.

In the whole sample, the dummy variable is introduced to test the significance of the impact of the interbank market and the exchange market on the test results. The dummy variable of the interbank market is set to 1 , and that of the exchange market is set to 0 . As shown in Table 14, the regression coefficient of the dummy variables has high significance, which indicates that the impact of the two trading markets on the spreads is significant in the normal period. However, the coefficient of the dummy variable is not significant in Table 13. The reason may be that liquidity and credit risk have a major impact on the spreads during the financial crisis. In the whole sample, the regression coefficients of Age, Coupon, and Age $*$ Coupon are significant at the level of $1 \%$, and the signs are in line with expectations during the financial crisis, while the regression coefficients of Vol, Age, Volatility, Coupon, Vol $*$ Volatility, Age $*$ Volatility, and Age $*$ Coupon are significant at the level of $1 \%$, and the signs are in line with expectations in the normal period. This shows that the impact of the interaction between liquidity and credit risk cannot be ignored. In addition, the coefficients of Age $*$ Volatility and Age $*$ Coupon increase from -0.0465 and -0.0489 to 0.0476 and -0.1432 , respectively, from the normal period to the financial crisis, because the interaction between liquidity and credit risk has a greater impact on the spreads during the financial crisis. And we study samples of Chinese corporate bond markets in the normal period and crisis period, respectively, and compare and analyze the empirical results. We find that liquidity risk and credit risk have highly persistent spreads, and the liquidity risk spreads of the price shock dimension produce a break point during the crisis, which is consistent with the findings of Sibbertsen et al. [62]; Wegener et al. [63]; Wegener et al. [64]; and Phillips and Shi [65].

To ensure the robustness of the results, we perform regression analysis of the interbank market and the exchange market independently. In the interbank market, similar results are found. The regression coefficients of Age, Coupon, and Age $*$ Coupon are significant at the level of $1 \%$, and the regression coefficients of Amihud and Amihud $*$ Coupon are significant at the level of $5 \%$ during the financial crisis. The regression coefficients of Amihud, Age, Coupon, Amihud $*$ Coupon, and Age $*$ Coupon are significant at the level of $1 \%$, and the signs are in line with expectations in normal times. This shows that the impact of the interaction between liquidity and credit risk cannot be ignored. In addition, the coefficients of Amihud $*$ Coupon and Age $*$ Coupon increase from -15.8072 and -0.0761 to -52.4023 and -0.1476 , respectively, from the normal period to the financial crisis period. On the exchange market, the regression coefficients of Day, Age, Coupon, and Age $*$ Coupon are significant at the level of $1 \%$ during the financial crisis. The regression coefficients of Vol, Volatility, Coupon, Vol $*$ Volatility, Age $*$ Coupon, and Vol $*$ Coupon are significant at the level of $1 \%$ in the normal period. This shows that the impact of the interaction between liquidity and credit risk cannot be ignored. In addition, the coefficient of Age * Coupon increases from -0.0221 to -0.1832 from the normal period to the financial crisis. This shows that the interaction between liquidity and credit risk is present in China's bond market and has a greater impact on the spreads during the financial crisis. 


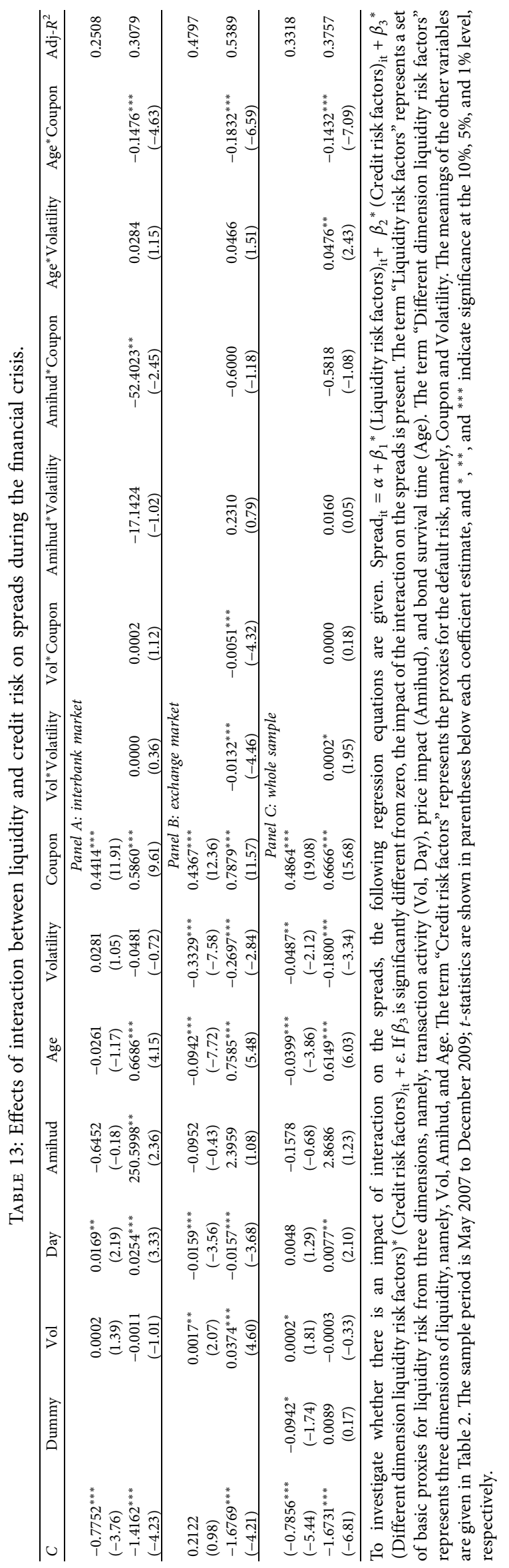




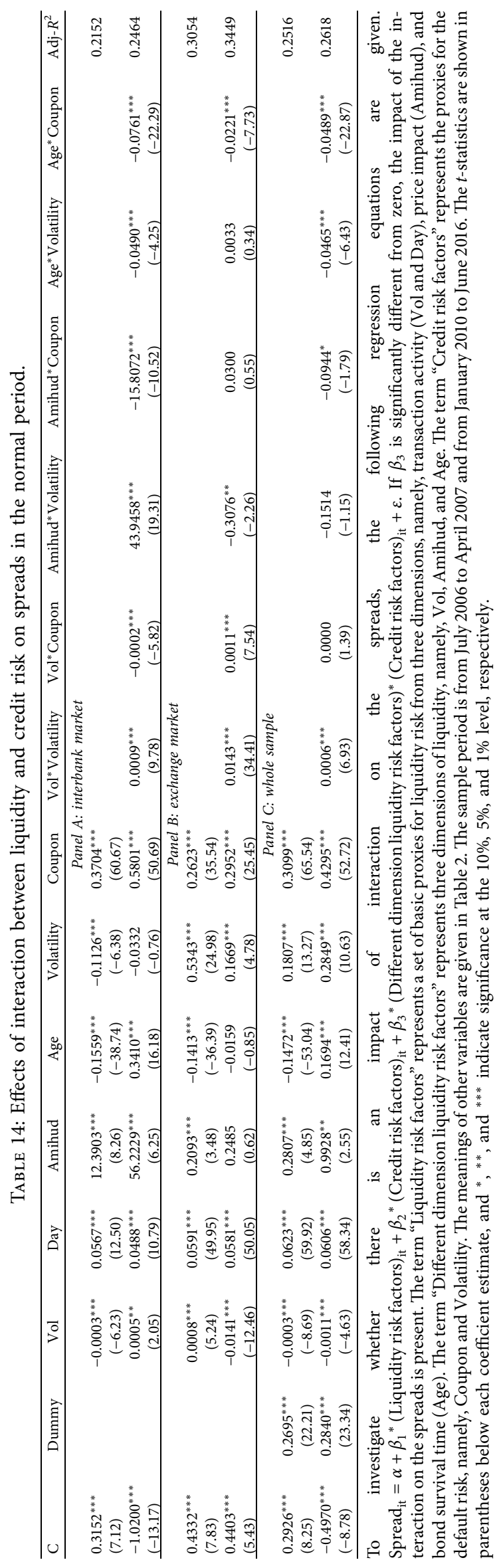




\section{Conclusion}

This study analyzes the impact factors of the price difference between the interbank market and the exchange market for the same bond in China. We identify 1224 individual bonds based on a large transaction dataset from July 2006 to June 2016 in China's bond market. The main conclusions are as follows.

First, we study the impact of liquidity on the price difference between the two markets for the same bond from different individual liquidity dimensions, such as trading activity and price shocks, and find that individual bond liquidity is an important factor affecting bond spreads, but it explains only a small part of spreads.

Second, we introduce the interaction between liquidity and credit risk into our models. Our study finds that interaction between credit risk and liquidity is an important factor influencing bond spreads, and this effect is greater during financial crisis. Some scholars provide several reasons. He and Milbradt [54] propose that starting from the observation that bond transaction costs increase in times of distress, a decrease in bond market liquidity results in rollover losses, which in turn increases default risk. According to Sperna Weiland et al. [56], the reason that higher credit risk can imply lower liquidity is the cost of market making. Our results produce the following reason: both liquidity and credit risk are closely related to market factors and macrofactors, and when market conditions change, liquidity and credit risk must comove and induce interaction. The greater the interaction between liquidity and credit risk, the more risk premium that investors demand.

Third, we find that market liquidity and macrofactors mainly affect the price difference between the two markets for the same bond. We choose proxies of different dimensions to investigate the explanatory power of market liquidity and macrofactors on spreads. The results are all robust.

Our study contributes to the literature by providing new explanatory channels on spreads. The results of this study offer interesting insights for corporate bond investors. In this study, we do not consider the problem of how to estimate a structural model to better capture the interaction by the theoretical models, which may be an important research direction in the future.

\section{Data Availability}

This study uses the data from the WIND database.

\section{Conflicts of Interest}

The authors declare that they have no conflicts of interest.

\section{Acknowledgments}

This work was supported by the National Natural Science Foundation of China (grant nos. 71471129 and 71501140) and Tianjin Philosophy and Social Science Planning Project (grant no. TJGL19-018).

\section{References}

[1] J. Dick-Nielsen, P. Feldhütter, and D. Lando, "Corporate bond liquidity before and after the onset of the subprime crisis," Journal of Financial Economics, vol. 103, no. 3, pp. 471-492, 2012.

[2] F. A. Longstaff, "The flight-to-liquidity premium in U.S. treasury bond prices," The Journal of Business, vol. 77, no. 3, pp. 511-526, 2004.

[3] D. Shin and B. Kim, "Liquidity and credit risk before and after the global financial crisis: evidence from the Korean corporate bond market," Pacific-Basin Finance Journal, vol. 33, pp. 38-61, 2015.

[4] A. Warga, "Bond returns, liquidity, and missing data," The Journal of Financial and Quantitative Analysis, vol. 27, no. 4, pp. 605-617, 1992.

[5] J. Helwege, J.-Z. Huang, and Y. Wang, "Liquidity effects in corporate bond spreads," Journal of Banking \& Finance, vol. 45, pp. 105-116, 2014.

[6] F. A. Longstaff, S. Mithal, and E. Neis, "Corporate yield spreads: default risk or liquidity? New evidence from the credit default swap market," The Journal of Finance, vol. 60, no. 5, pp. 2213-2253, 2005.

[7] L. E. Crabbe and C. M. Turner, "Does the liquidity of a debt issue increase with its size? Evidence from the corporate bond and medium-term note markets," The Journal of Finance, vol. 50, no. 5, pp. 1719-1734, 1995.

[8] M. Rossi, "Realized volatility, liquidity, and corporate yield spreads," Quarterly Journal of Finance, vol. 4, no. 1, Article ID 1450004, 2014.

[9] T. Chordia, A. Sarkar, and A. Subrahmanyam, "An empirical analysis of stock and bond market liquidity," Review of Financial Studies, vol. 18, no. 1, pp. 85-129, 2005.

[10] R. Y. Goyenko and A. D. Ukhov, "Stock and bond market liquidity: a long-run empirical analysis," Journal of Financial and Quantitative Analysis, vol. 44, no. 1, pp. 189-212, 2009.

[11] J. Ejsing, M. Grothe, and O. Grothe, "Liquidity and credit premia in the yields of highly-rated sovereign bonds," Journal of Empirical Finance, vol. 33, pp. 160-173, 2015.

[12] E. J. Elton, M. J. Gruber, D. Agrawal, and C. Mann, "Explaining the rate spread on corporate bonds," The Journal of Finance, vol. 56, no. 1, pp. 247-277, 2001.

[13] N. Friewald, R. Jankowitsch, and M. G. Subrahmanyam, "Illiquidity or credit deterioration: a study of liquidity in the US corporate bond market during financial crises," Journal of Financial Economics, vol. 105, no. 1, pp. 18-36, 2012.

[14] A. X. Wang, W. Z. Xie, and W. L. Yu, "Emprical research on China's corporate bond yield spread," Journal of Management Science, vol. 15, no. 5, pp. 32-41, 2012, in Chinese.

[15] H. Zhou, G. P. Li, W. F. Lin, and Y. Wang, "Analyze and progress of credit risk pricing model of corporate bonds," Journal of Management Sciences in China, vol. 18, no. 8, pp. 20-30, 2015, in Chinese.

[16] Y. Amihud, "Illiquidity and stock returns: cross-section and time-series effects," Journal of Financial Markets, vol. 5, no. 1, pp. 31-56, 2002.

[17] J. Bao, J. Pan, and J. Wang, "The illiquidity of corporate bonds," The Journal of Finance, vol. 66, no. 3, pp. 911-946, 2011.

[18] L. Chen, D. A. Lesmond, and J. Wei, "Corporate yield spreads and bond liquidity," The Journal of Finance, vol. 62, no. 1, pp. 119-149, 2007. 
[19] D. Covitz and C. Downing, "Liquidity or credit risk? The determinants of very short-term corporate yield spreads," The Journal of Finance, vol. 62, no. 5, pp. 2303-2328, 2007.

[20] F. De Jong and J. Driessen, "Liquidity risk premia in corporate bond markets," Quarterly Journal of Finance, vol. 2, no. 2, Article ID 1250006, 2012.

[21] C. Downing, S. Underwood, and Y. Xing, Is Liquidity Risk Priced in the Corporate Bond Market?, Rice University, Houston, TX, USA, 2005.

[22] P. Houweling, A. Mentink, and T. Vorst, "Comparing possible proxies of corporate bond liquidity," Journal of Banking \& Finance, vol. 29, no. 6, pp. 1331-1358, 2005.

[23] R. Roll, "A simple implicit measure of the effective bid-ask spread in an efficient market," The Journal of Finance, vol. 39, no. 4, pp. 1127-1139, 1984.

[24] O. Sarig and A. Warga, "Bond price data and bond market liquidity," Journal of Financial and Quantitative Analysis, vol. 24, no. 3, pp. 367-378, 1989.

[25] A. S. Kyle, "Continuous auctions and insider trading," Econometrica, vol. 53, no. 6, pp. 1315-1336, 1985.

[26] Z. Z. Ren and P. Li, "Impact of liquidity risk on the term structure of credit spreads," Journal of Systems and Management, vol. 15, no. 3, pp. 251-255, 2006, in Chinese.

[27] P. Brockman and D. Y. Chung, "Commonality in liquidity: evidence from an order-driven market structure," Journal of Financial Research, vol. 25, no. 4, pp. 521-539, 2002.

[28] C. Comerton-Forde, T. Hendershott, C. M. Jones, P. C. Moulton, and M. S. Seasholes, "Time variation in liquidity: the role of market-maker inventories and revenues," The Journal of Finance, vol. 65, no. 1, pp. 295-331, 2010.

[29] Z. H. Ji and Y. Y. Cao, "Credit risk premium or market liquidity premium? An empirical study on the pricing of credit bonds in China," Financial Research, vol. 440, no. 2, pp. 1-10, 2017, in Chinese.

[30] D. Bongaerts, F. De Jong, and J. Driessen, "An asset pricing approach to liquidity effects in corporate bond markets," The Review of Financial Studies, vol. 30, no. 4, pp. 1229-1269, 2017.

[31] P. Brockman, D. Y. Chung, and C. Pérignon, "Commonality in liquidity: a global perspective," Journal of Financial and Quantitative Analysis, vol. 44, no. 4, pp. 851-882, 2009.

[32] T. Chordia, R. Roll, and A. Subrahmanyam, "Commonality in liquidity," Journal of Financial Economics, vol. 56, no. 1, pp. 3-28, 2000.

[33] J. Hasbrouck and D. J. Seppi, "Common factors in prices, order flows, and liquidity," Journal of Financial Economics, vol. 59, no. 3, pp. 383-411, 2001.

[34] G. A. Karolyi, K.-H. Lee, and M. A. van Dijk, "Understanding commonality in liquidity around the world," Journal of Financial Economics, vol. 105, no. 1, pp. 82-112, 2012.

[35] R. A. Korajczyk and R. Sadka, "Pricing the commonality across alternative measures of liquidity," Journal of Financial Economics, vol. 87, no. 1, pp. 45-72, 2008.

[36] L. Mancini, A. Ranaldo, and J. Wrampelmeyer, "Liquidity in the foreign exchange market: measurement, commonality, and risk premiums," The Journal of Finance, vol. 68, no. 5, pp. 1805-1841, 2013.

[37] V. Acharya and L. Pedersen, "Asset pricing with liquidity risk," Journal of Financial Economics, vol. 77, no. 2, pp. 375-410, 2005.

[38] T. Chordia, R. Roll, and A. Subrahmanyam, "Market liquidity and trading activity," The Journal of Finance, vol. 56, no. 2, pp. 501-530, 2001.
[39] Ľ. Pástor and R. F. Stambaugh, "Liquidity risk and expected stock returns," Journal of Political Economy, vol. 111, no. 3, pp. 642-685, 2003.

[40] R. Sadka, "Momentum and post-earnings-announcement drift anomalies: the role of liquidity risk," Journal of Financial Economics, vol. 80, no. 2, pp. 309-349, 2006.

[41] U. N. Küçük, "Non-default component of sovereign emerging market yield spreads and its determinants: evidence from the credit default swap market," The Journal of Fixed Income, vol. 19, no. 4, pp. 44-66, 2010.

[42] S. Han and H. Zhou, "Effects of liquidity on the non-default component of corporate yield spreads: evidence from intraday transactions data," Quarterly Journal of Finance, vol. 6, no. 3, Article ID 1650012, 2016.

[43] Y. Guo, Z. Huang, and Y. Wang, "Unexpected monetary policy and credit spreads of corporate bonds in China: an empirical analysis using spreads of fixed and floating rate bonds," Journal of Financial Research, vol. 432, no. 6, pp. 67-80, 2016, in Chinese.

[44] S. C. Ludvigson and S. Ng, "Macro factors in bond risk premia," Review of Financial Studies, vol. 22, no. 12, pp. 5027-5067, 2009.

[45] P. Vodova, "Liquidity of Czech commercial banks and its determinants," International Journal of Mathematical Models and Methods in Applied Sciences, vol. 5, no. 6, pp. 1060-1067, 2011.

[46] N. Valla, B. Saes-Escorbiac, and M. Tiesset, "Bank liquidity and financial stability," Banque de France's Financial Stability Review, vol. 9, no. 1, pp. 89-104, 2006.

[47] V. Dinger, "Do foreign-owned banks affect banking system liquidity risk?" Journal of Comparative Economics, vol. 37, no. 4, pp. 647-657, 2009.

[48] M. A. B. Moussa, "The determinants of bank liquidity: case of Tunisia," International Journal of Economics and Financial Issues, vol. 5, no. 1, pp. 249-259, 2015.

[49] A. Singh and A. K. Sharma, "An empirical analysis of macroeconomic and bank-specific factors affecting liquidity of Indian banks," Future Business Journal, vol. 2, no. 1, pp. 40-53, 2016.

[50] H. Chen, R. Cui, Z. He, and K. Milbradt, "Quantifying liquidity and default risks of corporate bonds over the business cycle," The Review of Financial Studies, vol. 31, no. 3, pp. 852-897, 2017.

[51] D. Duffie and K. J. Singleton, "Modeling term structures of defaultable bonds," Review of Financial Studies, vol. 12, no. 4, pp. 687-720, 1999.

[52] J. Ericsson and O. Renault, "Liquidity and credit risk," The Journal of Finance, vol. 61, no. 5, pp. 2219-2250, 2006.

[53] Z. He and W. Xiong, "Rollover risk and credit risk," The Journal of Finance, vol. 67, no. 2, pp. 391-430, 2012.

[54] Z. He and K. Milbradt, "Endogenous liquidity and defaultable bonds," Econometrica, vol. 82, no. 4, pp. 1443-1508, 2014.

[55] J. Wang and C. Wu, "Liquidity, credit quality, and the relation between volatility and trading activity: evidence from the corporate bond market," Journal of Banking \& Finance, vol. 50, pp. 183-203, 2015.

[56] R. C. Sperna Weiland, R. J. Laeven, and F. De Jong, "Feedback between credit and liquidity risk in the US corporate bond market," in Proceedings of the 30th Australasian Finance and Banking Conference, Sydney, Australia, 2017.

[57] N. Dimic, J. Kiviaho, V. Piljak, and J. Äijö, "Impact of financial market uncertainty and macroeconomic factors on stockbond correlation in emerging markets," Research in International Business and Finance, vol. 36, pp. 41-51, 2016. 
[58] W. R. Gebhardt, S. Hvidkjaer, and B. Swaminathan, "Stock and bond market interaction: does momentum spill over?" Journal of Financial Economics, vol. 75, no. 3, pp. 651-690, 2005.

[59] S. T. Bharath and T. Shumway, "Forecasting default with the Merton distance to default model," Review of Financial Studies, vol. 21, no. 3, pp. 1339-1369, 2008.

[60] T.-K. Chen, H.-H. Liao, and P.-L. Tsai, "Internal liquidity risk in corporate bond yield spreads," Journal of Banking \& Finance, vol. 35, no. 4, pp. 978-987, 2011.

[61] H. Lin, J. Wang, and C. Wu, "Liquidity risk and expected corporate bond returns," Journal of Financial Economics, vol. 99, no. 3, pp. 628-650, 2011.

[62] P. Sibbertsen, C. Wegener, and T. Basse, "Testing for a break in the persistence in yield spreads of EMU government bonds," Journal of Banking \& Finance, vol. 41, pp. 109-118, 2014.

[63] C. Wegener, T. Basse, P. Sibbertsen, and D. K. Nguyen, "Liquidity risk and the covered bond market in times of crisis: empirical evidence from Germany," Annals of Operations Research, vol. 282, no. 1, pp. 407-426, 2019a.

[64] C. Wegener, R. Kruse, and T. Basse, "The walking debt crisis," Journal of Economic Behavior \& Organization, vol. 157, pp. 382-402, 2019 b.

[65] P. C. B. Phillips and S. Shi, "Detecting financial collapse and ballooning sovereign risk," Oxford Bulletin of Economics and Statistics, vol. 81, no. 6, pp. 1336-1361, 2019. 